\title{
On Line and Other ICTs Applications for Teaching Math in Special Education
}

\author{
http://dx.doi.org/10.3991/ijes.v2i4.4204 \\ Athanasios S. Drigas and Kostas S. Ioannis \\ NCSR DEMOKRITOS, Athens, Greece
}

\begin{abstract}
The term "students with special needs", "disabled" or "impaired students" is used to describe some students who have real, persistent, and substantial individual differences and educational needs that regular education has been unable to accommodate. These individual differences vary, from medical conditions such as cerebral palsy, to dyslexia, to pervasive and chronic maladaptive patterns of behaviour. These same students will and should not be considered disabled or impaired once they leave school. Nonetheless, their specialized learning needs are intense and legitimate because students with learning disabilities have significant difficulty acquiring and retaining math and other skills. ICTS are here to play an important role, offering the educators a valuable set of tools to cope with these difficulties. A number of factors are significant to the poor math performance of these students. In this review article we discuss these factors, the contribution of ICTS and make recommendations for a better math performance.
\end{abstract}

Index Terms-ICT, special education, learning difficulties, learning disabilities, teaching strategies, impaired students, math for special education.

\section{INTRODUCTION}

Students are all equal to the situations at the school. This is the aim of changing the teaching and learning at inclusive schools. Since the students' learning experiences and their ability to solve problems are different, they need different challenges, which inclusive schools provide if possible.

Due to changes of technology, society, and culture, the possibilities of the schools change all the time. Nowadays, the information and communication technology is often used to provide adequate challenges to all students [1].

Information and communications technology (ICT) is a useful phrase for summarizing the ways in which microchip technology has permeated many aspects of everyday life, in education, leisure, work and the home.

The term 'special educational needs' covers problems, related to particular impairments or related to learning and behavioral difficulties experienced by some learners compared with other similar learners.

ICT in many special schools has become an everyday and essential element of teaching and learning. Children with disabilities require modifications such as customized keyboards,voice synthesizers to use technology effectively

Special education researchers have developed research into the characteristics of students with mathematics learning disabilities from a developmental, neurological and neuropsychological, and educational perspective.
The role that teachers have in enabling effective ICT use for children is essential. The technology does nothing on its own but rather needs to be made to work in practice by the skill and perseverance of the school team [2].

\section{WHAT MAKES IT DIFFICULT TO LEARN MATHEMATICAL CONCEPTS AND SKILLS}

According to David Allsopp et al. (2003), students face difficulties in learning Mathematics. The development of mathematical understanding is affected by the following:

\section{A. Attention problems.}

Students displaying attention problems focus on everything that stimulate their senses but tend to be distracted from essential learning or problem-solving cues subsequently missing an important step in a problem solving procedure creating gaps in a student's knowledge base

\section{B. Cognitive-processing problems.}

Although students may have adequate vision and hearing, they may still have difficulty "interpreting" what they see or hear. For example, a student may see a math problem on the chalkboard but writes it inaccurately when he tries to write it, because of a disruption in the student's central nervous system that alters the message received from the visual system as it moves to the writing.

\section{Auditory problems}

Here the student may understand how to solve the problem, but that problem is not the one that the student processed cognitively. When the teacher relies primarily on one means of sensory input when modeling a mathematical concept, students who have cognitiveprocessing problems of this kind will not process the elements of the concept in the manner the teacher intends.

\section{Memory problems}

Students with memory problems cannot retrieve the necessary information accurately and quickly even though they may have successfully stored the information at one time. Faulty memory retrieval is especially problematic when students are confronted with multistep tasks, such as doing long division, solving algebraic equations, because these students often "mix up" or omit certain steps.

\section{E. Metacognitive deficits}

Metacognition is the ability to apply learning strategies, to evaluate their effectiveness and to change strategies when current ones are not successful. Students are not aware that others are using strategies to successfully complete the task, when students are expected to apply strategies they have learned to new situations, or skills. 


\section{Teaching Practices For Special NeEds Students}

\section{A. Professional Development of Teachers.}

A growing research base provides educators with a solid foundation for helping special needs students learn mathematics. Some of these strategies include the following:

- teaching in authentic and meaningful contexts;

- directly modeling general problem-solving strategies and learning strategies using multisensory techniques;

- ensuring that the sequence of instruction moves from the concrete, to the representational, to the abstract;

- describing mathematical understanding by the students;

- providing multiple practice opportunities to help students use their knowledge and build proficiency;

- and monitoring students' performance and offering meaningful feedback as performance charts

Individuals with Disabilities Education Act offers federal funding to the state and local education agencies providing special education for students who meet the criteria for eligibility, recognizes 13 different disability categories qualifying special education students.

\section{B. The 13 Qualifying Categories}

\section{a. Autism}

Autism, also referred to as Autism Spectrum Disorder, is a developmental disability that affects a child's ability to communicate, understand language, interact with others Autism is a syndrome, affecting the function of the brain is present from birth and apparent before the age of three.

\section{b. Deaf-Blindness}

Deaf-blindness is a medically verified hearing - visual impairment. Together, these impairments cause severe communication, developmental and education problems that cannot be accommodated in education programs for children with exclusive blindness or deafness.

\section{c. Deafness}

Deafness is a hearing impairment where children cannot understand what is being said even with the use of hearing aids, caused by a disease, toxicity, or injury.

\section{d. Emotional Disturbance}

Emotional disturbance, displays inability to learn, build, maintain inter-personal relationships that cannot be explained by intellectual, or health factors. displaying a mood of depression and a tendency to develop physical symptoms associated with personal or school problems.

\section{e. Hearing Impairment}

\section{f. Mental Retardation}

The severity of mental retardation is defined by an IQ test score and is described as mild when between $50-55$, moderate in the range of 35-40, severe within 20-25 and profound. A percentage of about $80 \%$ falls in the category of mild mental retardation.

Students with severe mental retardation belonging to the other three categories are more likely to show signs of complications, such as Down's syndrome, cerebral palsy, or defects affecting the central nervous system.

\section{g. Multiple Disabilities}

Students in this category require special educational services and related services including transportation, physical therapy, and need specialized equipment. Socialskills training and recreation programs can be an important component of services.

\section{h. Orthopedic Impairment}

\section{i. Other Health Impairment}

\section{j. Specific Learning Disability}

Attention deficit hyperactivity disorder is a neurological condition where students are described as inattentive, impulsive, and hyperactive. There has been a considerable rise in the number of students affected with $90 \%$ of them taking stimulant medication such as methylphenidate to control their behavior.

\section{k. Speech or Language Impairment}

Language impairments, unlike disorders of articulation, often result in substantial learning problems such as difficulties with language comprehension, expression, word-finding. Students display delayed speech, vocabulary development, reading. The major causes of language impairments are mental retardation, hearing impairment, central nervous system dysfunctions, and environmental factors such as lack of stimulation.

\section{l. Traumatic Brain Injury}

These students are likely to require both special educational services and related services. Related services include transportation, physical therapy, occupational therapy, speech therapy, psychological services, school health services. Schools provide specialized equipment needed by students. Social skills training and recreation programs are important services. Students who share strong recreational interests are likely to be integrated.

\section{m. Visual Impairment (Including Blindness)}

Although children with disabilities are a very diverse group, more than half of all students receiving special services are males, in elementary or middle school, that have problems that are primarily academic, emotional, social, or behavioral. [4]

\section{THE RELATIONSHIP BETWEEN VISUAL-SPATIAL REASONING ABILITY AND PROBLEM-SOLVING}

An important finding in Sean M Markey's enquiry in the field of math disability (MD) has sought to more clearly define the various, distinct cognitive profiles of students with MD. This has required an examination of the separate types of math problems that students face in the classroom, as well as an examination of the various cognitive abilities that underlie these separate groups of math problems. Three areas of difficulty which could each lead to MD, include, mastering and recalling basic number facts (number sense), language impairments, and visual-spatial difficulties [5]. 
In their research, Kovas et al. (2007), make a genetic study in 1.251 pairs of twins aged ten in the variation in five distinct mathematical domains which were: mathematical applications, understanding numbers, computation and knowledge, mathematical interpretation, and non-numerical processes. The findings showed that the heritability estimates were moderate and highly similar across domains. The environmental factors which are unique to each twin in a family explained most of the variances, and these factors were mostly specific to each domain. Students with MD tend to struggle with one or more of these domains. [6]

\section{A. Dyscalculia}

Butterworth (1999) describes dyscalculia as a specific learning difficulty in mathematics, in which children experience great difficulty understanding simple number concepts, lack an intuitive grasp of numbers and have problems learning number facts and procedures. Even when these children produce a correct answer or use a correct method, they tend to do so mechanically and without confidence. [7]

With the Dyscalculia Screener, diagnosis of dyscalculia is achieved by measuring response times to test items involving enumerating, understanding number size, numerals and simple arithmetic, in comparison with basic reaction time. [8]

Learning disabilities in math vary greatly depending on the child's strengths and weaknesses. A child's ability to do math will be affected differently by a language learning disability, or a visual disorder or a difficulty with memory or organization. A child with a math learning disorder may struggle with memorization and organization of numbers, operation signs, and number "facts" (like $5+5=10$ or $5 \times 5=25$ ). Children with math learning disorders might also have trouble with counting principles such as counting by $5 \mathrm{~s}$ or have difficulty telling time. [9]

Students with calculations difficulties may demonstrate problems with some or most of the following skills:

- Identifying the meaning of signs (e.g., -i-, x, <, =, \%, 2)

- Remembering answers to basic arithmetic combinations

- Using counting strategies to answer arithmetic problems

- Understanding the commutative property (e.g., $5+3=8$ )

- Solving multi-digit calculations that require regrouping.

- Misaligning numbers

- Ignoring decimal points

Word problem-solving difficulties:

- Reading the problem

- Understanding the meaning of the sentences

- Understanding what the problem is asking

- Identifying extraneous information that is not required for solving the problem

- Developing and implementing a problem solving plan

- Solving multiple steps in advanced word problems

- Using the correct calculations to solve problems

An examination of the behaviors cited across the studies demonstrates that difficulties are broad-based and exhibited across a wide array of mathematics content.

While individual students with mathematics LD may exhibit only one or two of the listed behaviors, they are more likely to exhibit pervasive difficulties. [10]

\section{PlanNING THE EFFECTIVE USE OF ICT IN TEACHING AND LEARNING MATHEMATICS:}

Graeme Brown et al. (2011) in their article illustrate how ICT can be a powerful, resource that mathematics teachers consider when planning work for their lessons. The selection and deployment of ICT resources should be made to fit the needs of the subject and not the reverse.

The rapid developments in ICT have lowered the costs. Many common ICT tools have been developed for personal use. Their deployment in a teaching environment requires careful consideration. In business it is a common rule that hardware accounts for less than half the investment in software, as well as training and support.

The resources spent to support the acquisition of software lags behind that of hardware so many software tools are generic which means they have not been specifically developed to support teaching and learning mathematics, because of the lack of support, funding, or knowledge of what is available.

The aim for ICT training is to equip teachers with the necessary knowledge, skills and understanding to decide how to use the appropriate ICT tools effectively in teaching. When used well, such tools make students active participants in the learning process. [11]

The Ofsted report (2002), contains the following useful statement in Paragraph 54: Good teaching using ICT begins with clarity of purpose in its use. Most often this comes with experience, and through thoughtful planning and collaboration between teachers integrating ICT into a scheme of work. Once pupils are working on their own or in groups, effective teaching involves teacher intervention to make sure that the objectives of the lesson are met. [12]

Kroesbergen et al. (2003) in his study for Children with Special Educational Needs concluded that for the learning of basic math facts, direct instruction appears to be most effective while for the learning of problem-solving skills, self-instruction methods are also quite effective.

With the use of a computer, it is possible to let children practice and automatize math facts and also to provide direct feedback. However, the computer cannot remediate the basic difficulties that the children encounter, as traditional interventions with humans as teachers, and not computers, are most effective.

Peer tutoring is when we have children work together to help and teach each other. It may be helpful and effective but it cannot replace instruction by an adult teacher.

\section{A Few Assistive Technology Success Stories}

Assistive technology is defined by the 1997 Individuals with Disabilities Education Act as "any item, piece of equipment, or product system, whether acquired commercially off the shelf, modified, or customized, that is used to increase, maintain, or improve functional capabilities of children with disabilities." These are few examples of progress in assistive technologies that have made substantial contributions to the lives of many people

\section{A. Kurzweil Reading Machine for the Blind}

Ray Kurzweil developed a reading machine for blind students over 20 years ago. It could "read" text using a computer scanner, and "speak" the text as output. Initially it was a bulky expensive device but technological progress has led to affordable handheld scanning devices. 


\section{B. Steven Hawking and ALS (Lou Gehrig Disease)}

Steven Hawking has been a worldwide role model of computer based communication aids for people with severe speech communication disabilities. Hawking has Amyotrophic Lateral Sclerosis a rare disease that attacks nerve cells in the brain and spinal cord causing total paralysis, yet, their minds remain sharp and alert.

\section{Cochlear Implant}

A large number of people are severely hearing impaired. The cochlear implant is a device that has restored some hearing capability to a great number of deaf people. [14]

\section{The BRAIN CAN CHANGE}

Science has made great advances in understanding the inner workings of the brain, making new discoveries that help people cope with learning disabilities and disorders. Neuroplasticity refers to the brain's natural, lifelong ability to change. Throughout life, the brain is able to form new connections and generate new brain cells in response to experience and learning.

New treatments for learning disabilities, take advantage of the brain's ability to change by using strategic brain exercises to identify and strengthen weak cognitive areas. For example, for children who have difficulty distinguishing between different sounds in a word, there are new computer-based learning programs that slow down the sounds so that children can understand them and gradually increase their speed of comprehension.

These discoveries about neuroplasticity provide hope to all students with learning disorders, and further research may lead to new treatments that target the actual causes of learning disabilities, rather than simply offering coping strategies to compensate for weaknesses. [15]

In his research Raul Valdés-Pérez (1999) describes the following successful systems based on these discoveries:

\section{A. The Arrowsmith program}

This program developed at the University of Chicago uses documents as a source of power.It makes conjectures about possible treatments or causes of medical diseases using collection of titles and abstracts from the medical literature. Given a target disease $\mathrm{C}$, the program searches for two associations $\mathrm{BC}$ and $\mathrm{AB}$ where $\mathrm{A}$ is typically a possible intervention that may cause or alleviate $\mathrm{C}$ through the intermediary B.

For example, the user may pose a $\mathrm{C}$ which is migraine, and the program may come up with $\mathrm{A}=$ magnesium and $\mathrm{B}=$ spreading depression. After subsequent human examination of the literature, reporting that "magnesium can inhibit spreading depression, which may cause migraine attacks," there is the suggestion that magnesium could be a treatment for migraine.

\section{B. The Graffiti program}

The University of Houston developed Graffiti, a program that makes mathematical conjectures in such domains as graph theory and geometry. Graffiti has motivated many graph theoreticians, to try to refute or prove the generated conjectures broadcast on an email list. Many of the program's conjectures have been proven and published as regular mathematical contributions.

The program keeps a database of previous conjectures so that when the program is run it will tend to produce novel conjectures. Every conjecture is tested against a file of qualitatively different graphs and thus becomes plausible if no counterexamples are found.

\section{The Mechem program}

This program finds explanatory hypotheses in chemistry, that is, given the chemicals that start a reaction and which are formed by it, as well as prior background knowledge expressed to the program as constraints, the task is to find all the simplest plausible reaction mechanisms that can explain how the products are formed. The program's mechanisms tend to contain novelty because the pieces that make up a hypothesis are not drawn from any stored catalogue of common reactions; rather, they are generated using a small number of steps toward particular solutions. [16]

\section{DifFICULTIES IN MATHEMATICS}

Students with learning disabilities often experience difficulty bridging informal mathematics namely concrete models of numbers to formal abstract mathematics curriculum such as symbols and mathematical annotation.

The sequence consists of three stages; the concrete, the representational. A sample problem is used below.

Sample Problem: Multiplication (Repeated Addition)

Objective: Student models multiplication as repeated addition of 3 groups of 4 , drawing a model, converting to the abstract mathematical language. Rachel gives 4 cookies to each of her 3 friends. How many cookies does she give out altogether?

\section{A. Concrete}

In the concrete stage, instruction proceeds through a sequence with each mathematical concept first modeled with concrete materials, i.e., red and yellow chips, cubes, base ten blocks, pattern blocks, fraction bars, etc. In the figure below, the student uses chips to represent cookies in the problem, 3 groups of 4 cookies. The concrete model must work together with teacher guidance, student interactions, teacher demonstrations and explanations, and many opportunities for students to practice and demonstrate mastery of concepts. Suggested materials and prompts are included in the teacher guidelines.

\section{B. Representational}

In the representational stage, the mathematics concept is modeled involving drawing pictures that represent concrete objects like circles, dots, tallies, stamps. For the sample problem above, the student uses circles to indicate cookies, and associates each group/friend with a box/oval around the cookies. Again, students are provided many opportunities for practice and to demonstrate mastery of the mathematics concept.

\section{Abstract}

In this stage, the mathematics concept is modeled at the abstract level using only numbers, notation and mathematical symbols. The student writes a numerical representation of the cookies to find the total $(4+4+4=$ 
12) through repeated addition or $(4 \times 3=12)$ through multiplication. Multiple opportunities for practice and demonstration should be provided to achieve mastery of the mathematics concept. [17]

\section{Impact Of At Usage On Education Of People With SPECIAL EDUCATIONAL NEEDS}

School education is vital and equal opportunity for children to develop as human beings, to know and understand the rules of the civil life, to relate and cooperate with their peers. The right to education for children with impairments, has been clearly stated at the international level in the so-called Salamanca Statement. "Every child has a fundamental right to education..." and "those with special educational needs must have access to regular school which should accommodate them within a child-centred pedagogy capable of meeting these needs."

Today the movement over the world includes students with disabilities into mainstream education, as they have equal opportunities to education and development as their peers. Didactics and pedagogy must change and adapt to build a school able to host all probable differences, to give all students suitable and personalized answers. [18]

\section{MATHEMATICS INTERVENTIONS FOR CHILDREN WITH SPECIAL EDUCATIONAL NEEDS}

Hearing Aids: It is a miniature public address system worn by the listener. It works best in quiet, structured settings, where the speaker is a few feet away and extraneous noise is minimized. School-age children most often use hearing aids, designed to fit behind the ear.

Frequency-Modulated (FM) Amplification Systems: Also known as an auditory trainer, the FM transmission device creates a direct link between the teacher and the student. Allowing them to move around the room.

Audio Loops: Sound may be transmitted through a wire connection or by using radio waves. Audio loops can be built into the walls of a room or created to surround only a certain section of seats in a room.

Infrared Systems: transmit clean, clear sound to hearing impaired listeners, providing better hearing in public places without the hassle of wires and cords.

Cochlear Implants: devices designed to provide sound information for people with hearing impairments by stimulating ear nerves of the inner ear and.

Braille Notetakers: Small devices that enable students to enter and store Braille characters in the form of words and sentences. They use the same six keys found on a traditional Braille writer but allow users to review their writings by listening to the text. Software translators allow the Braille to be converted into text.

\section{Input Devices for Students with Physical Disabilities}

Switches control the flow of electrical power to a device that the user wants to turn on or off. Switches can be activated by almost any part of the body a person is able to control. The movement must be controllable and reliable, and training is required before use.

Basic Adaptive Keyboards:Physically disabled students use computers by replacing standard keys with larger keys that are easier to see and touch, reducing the number of keys on the keyboard, placing keys in alphabetical order.
Touch-Sensitive Screens: This technology allows young computer users and individuals who have severe developmental or physical disabilities, to simply touch the computer screen to perform a function.

Infrared Sensors with Pneumatic Switches: These devices can enable physically disabled students to interact with the computer. As the user looks at the computer screen, the cursor follows the user's head movement. The pneumatic switch, enables the user to use the mouse.

Voice Recognition: Using voice recognition software, the user can bypass the keyboard and just speak to the computer. The reliability of the system can be enhanced by training the computer to recognize speech

\section{Special Education Students' Potential In MATHEMATICS ASSESSMENT}

Peltenburg et al. revealed that an ICT based assessment provides students in special education with more opportunities to show their mathematical capabilities in solving problems compared to a standardised assessment. The students attained a significantly higher percentage of correct answers in the ICT version of the test.

The match between the model and the strategy was not found in the students' responses. Another unexpected finding was that the indirect procedure was mostly used for solving a subtraction problem with a minuend and subtrahend which are not relatively close to each other. These indirect procedures were used in problems with a large difference between the numbers where the students used an empty number line which makes the strategy visible, while in the cases in which the numbers are relatively close to each other, the students are probably more inclined to mentally bridge the difference between the numbers. [20]

The integration of technology in mathematics education poses the question of its use at learning, teaching and research. Three factors emerge as decisive and crucial: the design, the role of the teacher, and the educational context.

The first factor concerns design of lessons and teaching in corresponding tasks and activities. The appropriate design enhances the co-emergence of technical mastery to use the digital technology for solving mathematical tasks, and the genesis of mental schemes that include the conceptual understanding of the mathematics at stake.

As a prerequisite, the pedagogical or didactical use in which the digital tool is incorporated should match with the tool's characteristics and affordances. Finally, the main guidelines and design heuristics should come from pedagogical and didactical considerations rather than being guided by the technology's limitations or properties.

The second factor concerns the role of the teacher, which is crucial. The integration of technology in math education is not a panacea. The teacher has to orchestrate learning, for example by synthesizing the results of technology activities, highlighting fruitful tool techniques.

The third and final factor concerns the educational context, which includes mathematical practices revealing how important it is that the use of digital technology is embedded in an educational context in which the work with technology is integrated in a natural way. [21]

Athanasios S. Drigas et al. indicate that in the latest years significant attempts have been made for an ICT assessment in mathematics. This is why several sets of 
teaching and training tools were designed to enhance pupils' learning experience.

Investigation has shown that the goal orientation change is a useful predictor for ICT infused mathematics intervention impact on slow learners. Software games for dyscalculia, aim at training children on an entertaining numeral comparison task by introducing problems adapted to the performance level of every individual. The results of this method indicated that this could be effective in the remediation of dyscalculia, for children aged 7-8 and under. [22]

Sean, a 15-year-old pupil living in the south of England finds a computer with a separate wireless screen to be a vital part of his education. He has been profoundly deaf from birth but is a high achiever and already has a grade $\mathrm{C}$ in math. His local authority provided support in the form of an audio typist who sat at his side and typed what was said in class to be read off a screen. However, Sean could not choose where he and his typist could sit in class. Plus the noise of the keyboard was distracting.

The remote wireless screen means that although he still has to have a hearing audio typist in the classroom, he does not have to sit next to him or her. He can be part of any group and join in the social interaction between his peers, as well as seeing the class discussion on screen and being able to concentrate more easily. [23]

\section{TEACHING STRATEgIES: MAKING USE OF BEST PRACTICE KNOWLEDGE}

Research and experience indicates that a simple theoryto-practice model fails to take account of the ways in which teachers do their work in regard to the complexities of the social and organizational relations in the wide variety of situations they face daily.

Behavioural, social constructivist and ecosystemic approaches to teaching and learning all contribute to pedagogy. The question is no longer which approach is best but how can we apply what has been learned from each of these models in ways that produce positive outcomes such as increased attainment and achievement.

Experience has shown that importing techniques that require high levels of attention to individual pupils is often unrealistic. Furthermore, the reliance on such approaches reinforces the belief that pupils with certain characteristics cannot be taught in ordinary school settings.

Expert teachers who respond to the diversity of learners needs found in every classroom, but in classrooms with a high proportion of children with special educational needs, have been found to embed a responsiveness to individual need within the context of whole class teaching.

Studies suggest that teaching is not a technical activity but one which involves making judgements and taking decisions. Teachers do not follow a single method but they draw on their knowledge and try out available ideas guided by their own beliefs and principles constrained by subject department, school policy, and available resources.

The limited research on implementation suggests that the adoption of practice is effected by such things as time to work on the innovation; acceptance of the importance of the intervention and teachers' perception of their technical competence. New research on innovation suggests the need to incorporate ways of examining the complex and non-linear patterns of teachers' work in their research designs. [24]

Data analysis revealed a categorization of skills where students were distributed according to their achievement in learning computer skills. These categories involve a basic skills, intermediate, and a literacy skills level. Across learned skills a correlation revealed relationship between keyboard, and academic skills, suggesting the significance of training as an essential component for further learning of academic objectives. Learning academic objectives such as reading, writing, and math was evidenced for students who were able to advance through the basic and intermediate skills categories.

Beyond the researchers' observations, the opinions of teachers and parents confirmed the positive impact of computer skills training on the students' learning experience. There is need for more research on the value of current and potential applications of ICT for students with special educational needs to position them among the major beneficiaries of the technology revolution. [25]

Teachers are comfortable with medium technologies, such as talking calculators and hand-held magnifiers, describing themselves as "IT illiterate" when referring to high-tech devices such as screen readers. Still others had subjective interpretations to technology.

Typically, students require support like speech access; Braille access; large print access; tactile communication systems or combinations of them. Teachers understand ICT and web educational packages designed for general instruction but are not aware of the available devices, so assistive technology is not adopted to benefit students.

While all teachers possessed limited skill and knowledge a few of them made extraordinary effort to acquire fundamental knowledge to help the assistive technology use amongst students with impairments. [26]

Tina James et al. for the development of an evaluation plan, showed the key elements not to be ignored:

- Local ownership and accountability are crucial if learning is to be gained and built on for future activities.

- Appropriate, realistic and measurable indicators should be selected to monitor outputs and outcomes.

- Monitoring activities should be clearly distinguished from the evaluations of performance criteria.

- All major stakeholders should be identified and involved in making decisions in the learning process.

- Adequate thought must be given in the implementation and what expected outcomes are desired.

- Costs should not be underestimated. [27]

\section{Learning from feedback:}

The computer often provides fast and reliable feedback which is impartial, encouraging students to make their own conjectures and to test out and modify their ideas.

Observing patterns: The speed of computers enables students to produce many examples when exploring mathematical problems and justifying of generalizations.

Seeing connections: The computer enables formulae, tables of numbers and graphs to be linked so changing one representation and seeing changes in the others helps students to understand connections between them.

Working with dynamic images: Students can use computers to manipulate diagrams and to visualize the geometry as they generate their own mental images. 
Exploring data: Computers enable students to work with real data which can be represented in a variety of ways. This supports interpretation and analysis.

Computer teaching: When students design algorithms to make a computer achieve a particular result, they express their commands unambiguously in the correct order. [28]

\section{Math education in Sub-Saharan African countries}

In Sub-Saharan African countries education is offered to a growing number of students at junior and senior secondary level. At secondary level math is compulsory in Burkina Faso, Botswana, Ghana, Nigeria, and Senegal. The following major trends in curriculum policy can be observed in the different countries:

- Localization of syllabi and examinations: all countries have localized curricula and examinations or are in the process of localization.

- "Education for All" policies, which have led to a growing and diverse student population, creating problems of mixed ability teaching in most countries. [29]

A coordinated interdisciplinary team approach to assessment and program planning is necessary. The consultants required depend on the individual student's disabilities and may include physiotherapists; speech and language pathologists; social workers; consultants for impairment students. It is vital that the student's needs be thoroughly assessed so that an appropriate educational program can be developed. [30]

\section{ASSISTIVE TECHNOLOGIES}

The use of assistive technology involves the learner using the tools and the teacher who learns to integrate it into teaching. Machines are not neutral, but an activity that influences students' and teachers' development.

This technology is about computing, graphing, problem solving, teaching by personalising and customising a given tool. Each user is an essential partner in the process of designing mathematical situations and resources.

We have learnt that teaching is a responsibility of the teacher, of course, but also of the students. The student configuration is considered as an essential contribution of students to teaching.

Mobile devices or tools for mathematics learning, might benefit students' out of school activities such as serious games, incorporated in multipurpose mobile technology, renewing the notion of artefacts for learning and teaching.

We need to be aware that technologies are no longer an isolated artifact, but integrated in and articulated with a network of resources, particularly online resources. [31]

\section{Integration of new material}

The teachers' professional development, must focus on teachers' interactions with digital resources and this is always connected with professional practice and beliefs. Professional and documentation systems evolutions do not always correspond to integration of new material.

Integration of new material remains an important issue, especially when the focus is on ICT. The study of a given teacher's documentation system also provides insights in the reasons for the integration or non-integration of a given material. [32]

Assistive technology for kids with learning disabilities is defined as any device, piece of equipment or system that helps bypass, work around or compensate for an individual's specific learning deficits. Although it doesn't cure or eliminate learning difficulties, it allows children to bypass areas of difficulty.

In general, assistive technology compensates for a student's skills deficits or areas of disability. However, a child can also receive remedial instruction. Research has shown that it can improve certain skill deficits such as reading and spelling, increasing a child's self-reliance and sense of independence. [33]

\section{Dealing With Math Learning Difficulties}

Math learning difficulties are worthy of serious attention as students may respond to repeated failure with withdrawal of effort, and lowered self-esteem. Math deficits have serious consequences on the management of everyday life causing difficulties with efficient recall of basic arithmetic facts and in written computation.

Language disabilities, even subtle ones, can interfere with math learning. In particular, students have a tendency to avoid verbalizing in math activities. Many children experience difficulty bridging informal math knowledge to formal school math. To build these connections takes time, experiences, and carefully guided instruction.

In sum, as special educators, there is much we can and need to do in this area that calls for so much greater attention than we have typically provided. [34]

\section{CONCLUSIONS}

ICTS can build the necessary bridge between the students' functioning and participation in school activities, offering them the possibility to learn through facilitating functional abilities, overcoming impairments, eliminating architectural barriers, supporting the student especially for mathematics. The process of school learning includes the development of traditional school activities; every child must have an opportunity to learn by playing, and later to learn traditional literacy: to write, draw, calculate, and read; these abilities, once acquired, will open his/her mind for the whole world.

\section{REFERENCES}

[1] Bent B. Andresen, "Using ICT in education to meet Special Needs. Sharing knowledge about best Practice," Copenhagen p. 1 , 2003.

[2] Lani Florian and John Hegarty, "ICT and Special Educational needs," Open University Press, 2004, pp. 2-3.

[3] David Allsopp, Louann Lovin, Gerald Green, and Emma SavageDavis, "Why Students with Special Needs Have Difficulty Learning Mathematics and What Teachers Can Do to Help," vol.8, no. 6, Mathematics Teaching In The Middle School: The National Council of Teachers of Mathematics, February 2003, pp.309-311.

[4] Jody L. Maanum, "Federal Special Education Disability Categories," Individuals with Disabilities Education Act (IDEA). The general educator's guide to special education. $3^{\text {rd }}$ ed., Corwin, 2009, pp. 2-114.

[5] Sean M Markey, "The relationship between visual-spatial reasoning ability and math and geometry problem-solving," ProQuest Dissertations and Theses, 2009.

[6] Kovas, Petril, and Plomin, "The Origins of Diverse Domains of Mathematics: Generalist Genes but Specialist Environments" in Journal of Educational Psychology. Feb 1, 2007, pp. 128-139.

[7] Brian Butterworth, "About Dyscalculia" in The Mathematical brain, London Macmillan, 1999, p. 1-2.

[8] Chris Singleton, "Using computer-based assessment to identify learning problems," in ICT and Special Educational needs, Lani Florian and John Hegarty, Eds. Open University Press, 2004, p.54 
[9] Gina Kemp, Melinda Smith, and Jeanne Segal, "Learning Disabilities \& Disorders. Types of Learning Disabilities and Learning Disorders and their Signs”, December 2013, p. 4.

[10] Brian R. Bryant and Diane Pedrotty Bryant, "Introduction to the special series: Mathematics and Learning Disabilities," in. Learning Disability Quarterly. vol. 31, Winter 2008, p.4.

[11] Graeme Brown et al., "ICT and Mathematics: a guide to learning and teaching mathematics," in Teacher Training Agency by The Mathematical Association, July 2002, pp. 4-5.

[12] Office for Standards in Education, "ICT in schools-Effect of the Initiatives," London 2002, p.16

[13] Evelyn h. Kroesbergen and Johannes e. H. Van Luit: Mathematics Interventions for Children with Special Educational Needs: A Meta-Analysis. Remedial and Special Education, Volume 24, Number 2, March/April 2003.

[14] David Moursund, "Introduction to Information and Communication Technology in Education," in Teacher Education, University of Oregon, 2005, pp. 94-96.

[15] Gina Kemp, Melinda Smith, and Jeanne Segal, "Learning Disabilities \& Disorders," in Helpguide.org, December 2013.

[16] Raul Valdés-Pérez, "Discovery tools for science apps," in Communications of the ACM, vol. 42, no. 11, November 1999, pp. 37-41 http://dx.doi.org/10.1145/319382.319389

[17] Terry Anstrom, "Supporting students in mathematics through the use of manipulatives," Centre for implementing technology in education, 2006, pp. 5-11.

[18] Edwards, Alistair et al. "ICTS in education for people with special needs," Specialized Training Course, UNESCO Institute for Information Technologies in Education, Moscow 2006, pp. 48.

[19] Ted S. Hasselbring Candyce H.Williams Glaser."Use of Computer Technology to Help Students with Special Needs," in The Future of Children. Children And Computer Technology, vol. 10 no.2, 2000, pp. 102-119.

[20] Peltenburg, Marjolijn, van den Heuvel-Panhuizen, Marja and Robitzsch, Alexander, "ICT-based dynamic assessment to reveal special education students' potential in mathematics," Research Papers in Education, vol. 25, no. 3, September 2010, pp.319-334. http://dx.doi.org/10.1080/02671522.2010.498148

[21] Paul Drijvers: Digital technology in mathematics education: Why it works (or doesn't). 12th International Congress on Mathematical Education. (8 July - 15 July, 2012, Seoul, Korea).

[22] Athanasios S. Drigas, Rodi-Eleni Ioannidou, "Special Education and ICTS," NCSR Democritos, Institute of Informatics and Telecommunications, Net Media Lab.

[23] Michael Harris, "What the research says about ICT supporting special educational needs and inclusion," British Educational Communications and Technology Agency, 2003.

[24] Al-Gawhary, Wedad and Kambouri, Maria, "The Impact of ICT as another route to overcome learning barriers for students with SEN: A Case Study in an Egyptian context," International Conference on Cognition and Exploratory Learning in Digital Age, 2012.

[25] Pauline Davis, Lani Florian, "Teaching Strategies and approaches for pupils with special needs: A Scoping Study," Faculty of Education, University of Cambridge. Department of education and skills: Research report 516, 2004.

[26] Wong Meng Ee and Libby Cohen, "Assistive Technology use amongst Students with Visual Impairments and Their Teachers
Barriers and Challenges in Special Education," NIE Research Brief No. 12-005, 2010.

[27] Tina James, Jonathan Miller, "Developing a monitoring and evaluation plan for ICT in education" in Monitoring and Evaluation of ICT in Education Projects: A Handbook for Developing Countries. Pre-publication draft for circulation at the World Summit on the Information Society, Tunis, November 2005, pp. 57-74

[28] Graeme Brown, Keith Cadman, David Cain, Alison ClarkJeavons, Roger Fentem, Alan Foster, Keith Jones, Adrian Oldknow, Ron Taylor, David Wright "ICT and Mathematics: a guide to learning and teaching mathematics Teacher Training Agency by The Mathematical Association," July 2002.

[29] Wout Ottevanger Jan van den Akker Leo de Feiter, "Developing Science, Mathematics, and ICT Education in Sub-Saharan Africa Patterns and Promising Practices," The World Bank, March 2007.

[30] Susan Carney, Connie Engbretson, Karen Scammell, Valarie Sheppard "Teaching Students with Visual Impairments: A guide for the support team," Saskatchewan Learning, Saskatchewan Canada, 2003.

[31] Luc Trouche, Paul Drijvers "Handheld technology for mathematics education: flashback into the future," ZDM Mathematics Education, Karlsruhe, 2010.

[32] Gueudet \& Trouche, "Teaching resources and teachers professional development: towards a documentational approach of didactics," in Proceedings of CERME, V. Durand-Guerrier, S. Soury-Lavergne, \& F. Arzarello, Eds., 2009, pp. 1359-1368.

[33] Kristin Stanberry, Marshall H. Raskind, "Assistive Technology for Kids with Learning Disabilities: An Overview," 2009.

[34] Kate Garnett "Math Learning Disabilities Division for Learning Disabilities," Journal of CEC, 1998.

\section{AUTHORS}

A. S. Drigas is a Senior Researcher at IIT-N.C.S.R. Demokritos. He is the Coordinator of Telecoms Lab and founder of Net Media Lab since 1996. From 1985 to 1999 he was the Operational manager of the Greek Academic network. He has been the Coordinator of Several International Projects, in the fields of ICTs, and e-services (e-learning, e-psychology, e-government, e-inclusion, eculture etc). He has published more than 260 articles, 7 books, 25 educational CD-ROMs and several patents. He has been a member of several International committees for the design and coordination of Network and ICT activities and of international conferences and journals. (e-mail: $\mathrm{dr} @$ iit.demokritos.gr)

J. S. Kostas is an Associate Professor of New Technologies at public primary and secondary schools in Athens, Greece. (e-mail: iikostas@sch.gr)

Submitted 10 October 2014. Published as resubmitted by the authors 25 October 2014. 